\title{
EFICIÊNCIA DA UTILIZAÇÃO DO CRÉDITO RURAL E DO CAPITAL SOCIAL NA AQUICULTURA DOS ESTADOS BRASILEIROS NO ANO DE 2011
}

\author{
Adauto Brasilino Rocha Junior ${ }^{1}$, Omar Jorge Sabbag ${ }^{2}$, Silvia Maria Almeida Lima Costa², \\ Jaqueline Bonfim de Carvalho ${ }^{3}$ \\ ${ }^{1}$ Graduando em Agronomia na Faculdade de Engenharia / UNESP Campus de Ilha Solteira (SP). \\ 2 Docente do Departamento de Fitotecnia, Tecnologia de Alimentos e Socio Economia da Faculdade de \\ Engenharia / UNESP Campus de Ilha Solteira (SP). \\ ${ }^{3}$ Engenheira Agrônoma pela Faculdade de Engenharia / UNESP Campus de Ilha Solteira (SP).
}

RESUMO: O presente trabalho consiste na aplicação da análise envoltória de dados para o estabelecimento de um ranking de eficiência da utilização conjunta dos inputs crédito rural, oferecido para a aquicultura; e do capital social (recurso financeiro disponibilizado na forma de convênios relacionados à atividade); para o incremento da produção aquícola nos estados brasileiros entre 2010 e 2011. Foi utilizado o modelo BCC com orientação a output, que indica qual o maior nível de produção que se pode alcançar considerando o valor de inputs disponíveis. Os estados do Mato Grosso, Paraíba e Maranhão ocuparam o $1^{\circ}, 2^{\circ}$, e $3^{\circ}$ lugar do ranking, respectivamente. $\mathrm{O}$ estado do Acre apresentou a menor eficiência entre as DMU's analisadas, sendo que os principais fatores condicionantes de eficiência observados foram o aproveitamento de espécies nativas, com nicho diferenciado e maior valor de mercado; o ordenamento legal da atividade e o apoio através de incentivos fiscais por parte do governo estadual; e a existência de um ambiente institucional bem estruturado e que atenda a demanda regional de informação e assistência técnica e a agilidade nos processos de licenciamento, por meio da participação ativa dos governos municipal e estadual. Conclui-se que a análise DEA é um interessante instrumento de auxílio governamental, pois permite que além dos valores absolutos de insumos e de produção, possam ser observados outros condicionantes, que passariam despercebidos perante uma análise comum.

Palavras-chave: Política. Piscicultura. Análise DEA.

\section{EFFICIENCY USE OF RURAL CREDIT AND SOCIAL CAPITAL IN AQUACULTURE OF BRAZILIAN STATES IN 2011}

\begin{abstract}
The present paper is the application of data envelopment analysis to establish a ranking of efficiency combined use of rural credit inputs, offered for aquaculture; and social capital (financial resources available in the form of agreements related to the activity); to increase aquaculture production in the Brazilian states between 2010 and 2011. We used the BCC model with output orientation, which indicates that the highest level of production that can be achieved considering the amount of available inputs. The states of Mato Grosso, Paraíba and Maranhão occupied the 1st, 2nd, and 3rd place ranking, respectively. The state of Acre had the lowest efficiency among the DMU's analyzed, and
\end{abstract}

Cultura Agronômica, Ilha Solteira, v.24, n.4, p.355-368, 2015 
the main observed efficiency of conditioning factors were the use of native species, with different and higher market value; the legal framework of the activity and support through tax incentives by the state government; and the existence of a well-structured and institutional environment that meets regional demand for information and technical assistance and agility in the licensing process, through the active participation of municipal and state governments. We conclude that the DEA analysis is an interesting government aid instrument because it allows addition of the absolute values of input and output, can be observed other conditions that goes unnoticed before a common analysis.

Key words: Politics. Fish Farming. DEA Analysis.

\section{INTRODUÇÃO}

A partir de 2009, com a transformação da então Secretaria Especial da Aquicultura e Pesca (SEAP) em Ministério da Pesca e Aquicultura (MPA), as discussões referentes à consolidação do setor aquícola e desenvolvimento sustentável da atividade tomaram outra dimensão. Para atender à demanda de informações sobre o setor, o MPA lançou o Boletim Estatístico da Pesca e Aquicultura, em 2011, que apresenta informações sobre a produção pesqueira nacional.

Considerando o estágio organizacional do setor aquícola, a organização e o estabelecimento de redes entre os empreendimentos que atuam no setor mostram-se fundamentais quando tratamos de um segmento em que a produção é pulverizada pelo território nacional, pois a maioria dos empreendimentos aquícolas são microempresas ou empresas não operacionais (SIDONIO et al., 2012). Nesse contexto, é importante considerar o capital social, definido por Milani (2007), como o somatório de recursos inscritos nos modos de organização cultural e política da vida social de uma população; entretanto, a análise do capital social é bastante complexa, tratando-se de um recurso abstrato, mas o conjunto de valores que constituem esse capital se manifesta através de conquistas que atendem ao interesse comum entre as partes que se relacionam.

Assim, um modo de avaliar esse capital é através da quantificação do recurso financeiro utilizado por meio de convênios firmados, pois estes instrumentos caracterizam uma forma de ajustamento entre partícipes para a realização de interesses comuns, mediante mútua colaboração (BRASIL, 2013).

Uma ferramenta útil para a interpretação da eficiência dos Estados brasileiros na utilização desses recursos (crédito rural e capital social) é a análise envoltória de dados (data envelopment analysis - DEA). Neste contexto, o presente trabalho teve por objetivo avaliar a eficiência da utilização do crédito rural e do capital social na produção aquícola nos 26 estados brasileiros, investigando os possíveis condicionantes da eficiência, a partir dos Estados mais eficientes.

Cultura Agronômica, Ilha Solteira, v.24, n.4, p.355-368, 2015 


\section{MATERIAL E MÉTODOS}

Para determinar a eficiência da utilização do crédito rural e do capital social na aquicultura dos estados brasileiros, o presente trabalho baseou-se em dados secundários, em que foram utilizados como insumos relevantes promotores do desenvolvimento da aquicultura (designados como inputs) o valor em reais $(\mathrm{R} \$$ ) do crédito rural oferecido para a atividade aquícola em cada estado no ano de 2010; e o valor em reais dos recursos financeiros disponibilizados para o fomento da aquicultura na forma de convênios vigentes entre Junho de 2010 e Junho de 2011. Como resultado ou produto da estruturação produtiva, definiu-se como output o incremento na produção de pescados, em toneladas, de 2010 para 2011.

O valor do crédito rural oferecido para a atividade aquícola no ano de 2010 foi determinado através do anuário estatístico do crédito rural de 2010, publicado pelo BNDES, onde constam os valores de crédito rural oferecidos por atividade, e por estado. A obtenção dos valores dos recursos financeiros formais colocados à disposição da aquicultura foi possível somando-se, para cada estado, os valores aportados para créditos nas modalidades de financiamento a custeio, investimento, e comercialização para empreendimentos tanto de águas continentais como de águas marinhas (em piscicultura, malacocutura, carcinicultura e ranicultura). Considerou-se que a resposta ao crédito rural e aos convênios ocorre na safra de 2011, devido à duração dos ciclos de produção de pescado e à burocracia de acesso aos recursos.

Para a quantificação do capital social utilizou-se como indicador o valor, em reais, correspondente à soma dos recursos disponibilizados através de convênios relacionados à aquicultura, vigentes em cada estado entre o período de Junho de 2010 à Junho de 2011. Esse horizonte temporal foi escolhido levando-se em conta que a duração média do ciclo das espécies aquícolas cultivadas foi de seis meses, portanto os convênios formalizados neste período afetam a produção aquícola do ano de 2011. Os dados utilizados para esse levantamento estão disponíveis no Sistema Integrado de Administração Financeira do Governo Federal - SIAFI e do Sistema de Convênios - SICONV e atualizadas periodicamente. Já a produção de pescados no ano de 2011 foi determinada a partir do Boletim Estatístico da Pesca e Aquicultura de 2011, publicado pelo Ministério da Pesca e Aquicultura.

Ressalta-se que a metodologia DEA foi desenvolvida por Charnes et al. (1996), e foi baseada em estudos sobre eficiência elaborados por Farrel (1957). O objetivo deste referencial é calcular a eficiência relativa de unidades tomadoras de decisão (designadas como DMU's ${ }^{1}$ ), com múltiplos insumos e produtos (NEVES JÚNIOR et al., 2012). Trata-se ainda de uma técnica de programação matemática, não estocástica (probabilística) e não paramétrica utilizada para medir a eficiência das DMU's, pois ao focalizar a eficiência da relação entre inputs e outputs não requer a especificação explícita da forma funcional desta

\footnotetext{
${ }^{1}$ As DMU's correspondem às unidades de análises relevantes para a análise em consideração, podendo ser empresas. No caso desta abordagem são os Estados da Federação.
}

Cultura Agronômica, Ilha Solteira, v.24, n.4, p.355-368, 2015 
relação.

Assim, para cada DMU utilizada na análise DEA, resolve-se um problema matemático em que é determinada uma fronteira de eficiência padrão, que pode ser uma reta (modelo CCR - constante de escala) ou uma curva (modelo BCC - variável de escala), que represente a fronteira produtiva para determinadas combinações de inputs utilizados com $100 \%$ de eficiência; e uma fronteira de eficiência invertida, em que os outputs são considerados como inputs e os inputs como outputs. A Figura 1 representa as fronteiras de eficiência padrão e invertida para um input e um output.

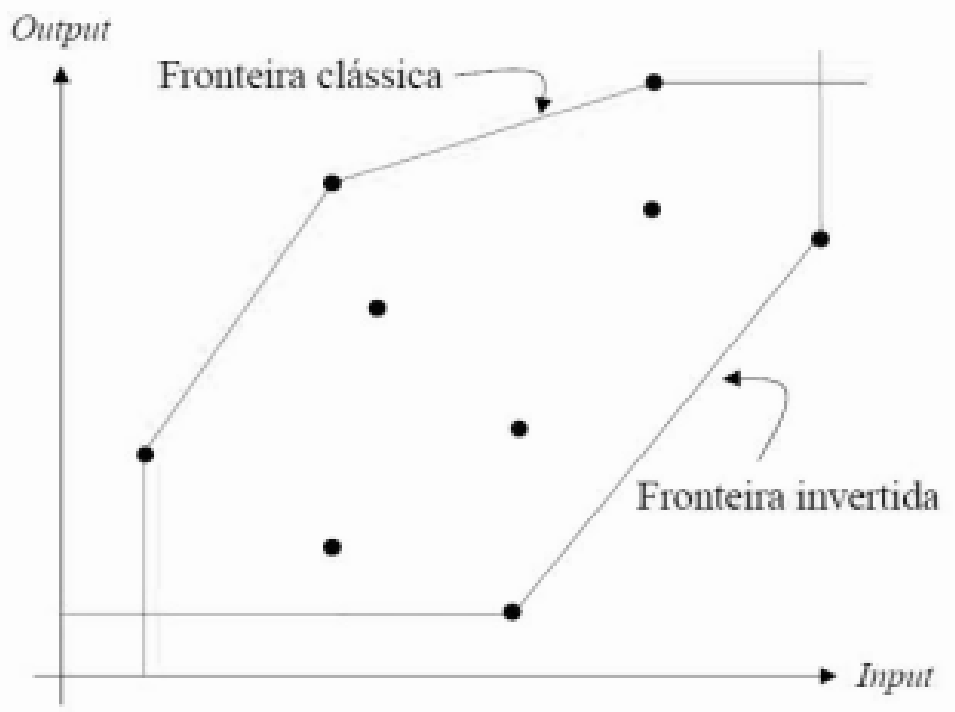

Figura 1. Fronteiras de eficiência padrão e invertida.

Fonte: Angulo-Meza et al. (2005).

As DMU's mais próximas da fronteira invertida apresentam as piores práticas gerenciais. Por fim, a análise DEA-BCC retorna os valores de eficiência padrão (quanto mais próxima da fronteira de eficiência padrão estiver a DMU, mais próximo de 1 será esse valor); de eficiência invertida (quanto mais próxima da fronteira invertida, mais próximo de 1 esse valor); de eficiência composta (diretamente proporcional à proximidade da fronteira de eficiência padrão e à distância da fronteira invertida); e de eficiência composta normalizada (dividindo-se o valor da eficiência composta da DMU pelo maior valor dentre todas as eficiências compostas). As expressões abaixo representam estas interações:

Eficiência Composta = Eficiência Padrão + (1 - Eficiência Invertida) / 2;

Eficiência Composta Normalizada = Eficiência Composta / Máxima Eficiência Composta

O modelo DEA utilizado na análise desse trabalho foi o Modelo Variável de Escala (BCC) com orientação a output. Esse modelo foi escolhido por ser o mais adequado aos objetivos do estudo, pois pressupõe que as unidades avaliadas apresentam retornos variáveis de escala, ou seja, que o aumento da produção com o acréscimo de unidades de input não é linear, o que confere maior aproximação da realidade. O referido modelo procurou responder à questão: "Dado o nível de recursos utilizados, qual o maior nível de produção que se pode alcançar mantendo-se o nível dos inputs (recursos) constante?" 
A formulação matemática do Modelo BCC-output utilizado neste trabalho, pode ser expressa conforme segue:

$$
\begin{aligned}
& \operatorname{Max} h_{0} \text { sujeito } \grave{a}: \\
& x_{i o} \geq \sum_{k=1}^{n} x_{i k} \lambda_{i k} \forall i, \\
& h_{0} y_{j 0} \leq \sum_{k=1}^{n} y_{j k} \lambda_{k}, \forall j, \\
& \lambda_{k} \geq 0, \forall k .
\end{aligned}
$$

Em que: $h_{0}$ é a medida radial de eficiência técnica; $y_{i}$ é o valor do output i; $x_{j}$ é o valor do input j e $l_{k}$ é a importância da DMU k como referência para DMU 0.

Para a análise DEA foi utilizado o software SIAD (Sistema Integrado de Apoio à Decisão), versão 3.0 (MEZA et al., 2005), desenvolvido para resolver os problemas de programação linear da Análise Envoltória de Dados. Ele fornece como resultados as fronteiras de eficiência padrão, invertida, composta e composta normalizada, além dos resultados de metas (alvo) e de melhoria (folga). Os resultados foram utilizados para o estabelecimento de um ranking de eficiência entre os estados brasileiros e para a identificação de estados referência para benchmarking nos esforços de fomento à aquicultura.

\section{RESULTADOS E DISCUSSÃO}

$\mathrm{O}$ input valor em reais $(\mathrm{R} \$)$ do crédito rural oferecido para a atividade aquícola evidencia íntima relação com os resultados produtivos, uma vez que a expansão da produção total de pescado oriundo da aquicultura é dada pelo aumento da produtividade dos empreendimentos já existentes ou pelo aumento da escala produtiva, por meio da expansão da atividade em novas áreas. Nos casos analisados, o aumento na produção decorre primordialmente da realização de investimentos, que são oriundos basicamente pelo crédito rural, o qual, segundo Rezende (1981), oferta capital financeiro em condições de taxa de juro e de reembolso mais vantajosas do que as vigentes no mercado financeiro livre.

A quantificação do capital social como valor em reais dos recursos financeiros disponibilizados para o fomento da aquicultura na forma de convênios é um input tão interessante quanto o crédito rural, ao representar materialmente a construção das relações de mútua colaboração entre partícipes. Essa ideia encontra correspondência com a definição de capital social apresentada por Coleman (1990), citado por Marques (2001), segundo o qual o capital social é criado quando as relações entre as pessoas ou instituições mudam de acordo com as formas que facilitam a ação.

Os convênios identificados consistiram principalmente em projetos para capacitação técnica nas atividades de aquicultura, para construção e melhorias de infraestrutura na 
cadeia produtiva de pescados, demarcação de áreas propícias para a produção em águas continentais e costeiras (parques aquícolas), instalação de unidades demonstrativas de piscicultura, construção de fábricas de gelo e frigoríficos, projetos de pesquisa na área, dentre outros. Todos esses convênios, portanto, representam uma relação de confiança entre o órgão que disponibiliza o recurso e o convenente, que o solicita através de projetos e o custo dos projetos apresenta uma relação proporcional com o impacto na atividade.

Tabela 1. DMU's, output, e inputs considerados na análise DEA.

\begin{tabular}{|c|c|c|c|}
\hline Estados (DMU's) & $\begin{array}{c}\text { Incremento na } \\
\text { produção de } \\
\text { pescados entre } 2010 \text { - } \\
2011 \text { (Ton.) }(\text { (O1) } \\
\end{array}$ & $\begin{array}{c}\text { Crédito } \\
\text { Oferecido em } \\
2010(\mathrm{R} \$)(\mathrm{I} 1)\end{array}$ & $\begin{array}{c}\text { Valor dos Convênios } \\
\text { - Aquicultura } \\
(06 / 2010-06 / 2011) \\
(\text { I2) } \\
\end{array}$ \\
\hline Acre & $1.621,70$ & $385.0826,38$ & $8.362 .649,52$ \\
\hline Alagoas & $-2.824,30$ & $384.459,16$ & $2.596 .380,71$ \\
\hline Amapá & 274,20 & $73.035,54$ & $796.558,45$ \\
\hline Amazonas & $15.712,00$ & $6.221 .435,45$ & $8.630 .937,92$ \\
\hline Bahia & $2.433,90$ & $1.040 .883,3$ & $33.073 .923,23$ \\
\hline Ceará & $5.851,00$ & $6.628 .808,22$ & $11.544 .550,03$ \\
\hline Espírito Santo & $3.922,00$ & $1.055 .546,53$ & $1.285 .402,00$ \\
\hline Goiás & $-5.102,70$ & $2.221 .904,22$ & $1.962 .455,93$ \\
\hline Maranhão & $30.602,30$ & $9.477 .952,34$ & $13.259 .661,43$ \\
\hline Mato Grosso & $13.415,30$ & $951.637,48$ & $1.780 .137,41$ \\
\hline Mato Grosso do Sul & $-2.070,00$ & $3.456 .202,91$ & $5.396 .670,73$ \\
\hline Minas Gerais & $14.299,80$ & $8.335 .539,74$ & $3.286 .660,90$ \\
\hline Pará & $6.133,90$ & $6.625 .802,93$ & $19.980 .605,12$ \\
\hline Paraíba & $4.723,90$ & $789.291,52$ & $909.893,12$ \\
\hline Paraná & $37.226,20$ & $14.597 .588,32$ & $9.704 .229,24$ \\
\hline Pernambuco & $6.566,00$ & $291.563,82$ & $5.861 .309,32$ \\
\hline Piauí & $12.643,20$ & $2.186 .682,72$ & $180.000,00$ \\
\hline Rio de Janeiro & $-1.365,00$ & $3.276 .516,19$ & $2.204 .988,77$ \\
\hline Rio Grande do Norte & $-3.874,20$ & $920.639,89$ & $3.626 .867,89$ \\
\hline Rio Grande do Sul & $-28.884,20$ & $3.891 .902,8$ & $2.949 .081,60$ \\
\hline Rondônia & $2.608,30$ & $6.915 .829,49$ & $434.040,28$ \\
\hline Roraima & $21.095,00$ & 2.999.910,90 & $2.167 .000,00$ \\
\hline Santa Catarina & $14.079,59$ & $7.743 .152,07$ & $16.146 .755,13$ \\
\hline São Paulo & $-1.717,70$ & $9.820 .356,83$ & $7.296 .139,93$ \\
\hline Sergipe & $-2.524,30$ & $123.710,97$ & $259.068,47$ \\
\hline Tocantins & $5.434,30$ & $608.865,89$ & $135.205,00$ \\
\hline TOTAL & $674.729,40$ & $104.490 .045,61$ & 788 \\
\hline Maior & Paraná & Paraná & Bahia \\
\hline Menor & Rio Grande do Sul & Distrito Federal & Tocantins \\
\hline Média & $5.780,01$ & $3.870 .001,68$ & $6.301 .198,93$ \\
\hline Desvio padrão & $8.772,63$ & $3.078 .396,39$ & $5.483 .743,17$ \\
\hline
\end{tabular}

Fonte: BNDES (2010); BRASIL (2014); BRASIL (2012a). 
Desta forma, a Tabela 1 apresenta as variáveis para análise de eficiência no presente trabalho, bem como as estatísticas descritivas das variáveis de análise de eficiência dos Estados produtores. Percebe-se que o desvio padrão médio é bastante alto, o que é explicado parcialmente pela dimensão territorial do Brasil, que propicia diferenças significativas quanto à abundância e qualidade de recursos hídricos entre as diferentes unidades de federação e também devido à diferença quanto à tradição em explorações aquícolas nas regiões do país.

O maior produtor de pescado no ano de 2011 foi o Paraná, que também apresentou maior incremento na produção e a maior demanda de crédito. O estado do Paraná apresenta grande abundância de recursos hídricos e a maior parte da produção (80\% da produção em 2010, segundo o MPA) é de tilápia, peixe exótico bem estabelecido no clima tropical brasileiro e de alta produtividade e aceitação nos mercados nacional e internacional.

O Distrito Federal não foi considerado na análise DEA, pois não apresentou demanda de crédito em 2010. Os Estados de Alagoas, Goiás, Mato Grosso do Sul, Rio de Janeiro, Rio Grande do Norte, Rio Grande do Sul, São Paulo e Sergipe apresentaram diminuição na produção aquícola entre os anos de 2010 e 2011, portanto também não puderam ser considerados na análise.

Na Tabela 2 são apresentados os valores de eficiência encontrados para os estados brasileiros no ano de 2011.

Tabela 2. Valores de eficiência para as DMU's no ano de 2011.

\begin{tabular}{lrrrr}
\hline $\begin{array}{l}\text { Estados } \\
\text { (DMU's) }\end{array}$ & $\begin{array}{r}\text { Eficiência } \\
\text { Padrão }\end{array}$ & $\begin{array}{r}\text { Eficiência } \\
\text { Invertida }\end{array}$ & $\begin{array}{r}\text { Eficiência } \\
\text { Composta }\end{array}$ & $\begin{array}{r}\text { Eficiência Composta } \\
\text { normalizada }\end{array}$ \\
\hline Acre & 0,068145 & 1,000000 & 0,034072 & 0,034916 \\
Amapá & 1,000000 & 1,000000 & 0,500000 & 0,512384 \\
Amazonas & 0,567401 & 0,209515 & 0,678943 & 0,695759 \\
Bahia & 1,000000 & 1,000000 & 0,500000 & 0,512384 \\
Ceará & 0,220828 & 0,353377 & 0,433725 & 0,444468 \\
Espírito Santo & 0,431638 & 0,123339 & 0,654150 & 0,670351 \\
Maranhão & 1,000000 & 0,082431 & 0,958784 & 0,982531 \\
Mato Grosso & 1,000000 & 0,048337 & 0,975831 & 1,000000 \\
Minas Gerais & 0,691975 & 0,126855 & 0,782560 & 0,801942 \\
Pará & 0,290693 & 0,576893 & 0,356900 & 0,365740 \\
Paraíba & 1,000000 & 0,066812 & 0,966594 & 0,990534 \\
Paraná & 1,000000 & 1,000000 & 0,500000 & 0,512384 \\
Pernambuco & 1,000000 & 0,093458 & 0,953271 & 0,976881 \\
Piauí & 1,000000 & 1,000000 & 0,500000 & 0,512384 \\
Rondônia & 1,000000 & 1,000000 & 0,500000 & 0,512384 \\
Roraima & 1,000000 & 0,009930 & 0,950350 & 0,973888 \\
Santa Catarina & 0,529321 & 0,325698 & 0,601812 & 0,616717 \\
Tocantins & 1,000000 & 1,000000 & 0,500000 & 0,512384 \\
\hline
\end{tabular}

Fonte: elaboração do autor, a partir dos dados de software.

Cultura Agronômica, Ilha Solteira, v.24, n.4, p.355-368, 2015 
Pela medida da eficiência padrão, percebe-se que a fronteira de eficiência é composta por 11 estados brasileiros, o que dificulta o estabelecimento de um ranking e a identificação do estado mais eficiente para servir de benchmarking para os demais estados com menor eficiência. Assim, a discriminação pode ser feita a partir da fronteira invertida, pois todos os estados eficientes na fronteira padrão teoricamente passariam ao status de ineficientes na segunda fronteira e vice-versa.

Desta forma, os valores de eficiência composta e composta normalizada, que são diretamente proporcionais à proximidade da fronteira da eficiência padrão e a distância da fronteira invertida, contribuíram para o critério de desempate entre as eficientes, observado pela Tabela 3, que representa o ranking da eficiência dos estados brasileiros no uso do crédito rural e do capital social.

Tabela 3. Ranking de eficiência da utilização do crédito rural e do capital social na aquicultura pelos estados brasileiros.

\begin{tabular}{|c|c|c|}
\hline$\overline{\text { Posição }}$ & Estados (DMU's) & Eficiência \\
\hline $1^{\circ}$ & Mato Grosso & $100,00 \%$ \\
\hline $2^{o}$ & Paraíba & $99,05 \%$ \\
\hline $3^{\circ}$ & Maranhão & $98,25 \%$ \\
\hline $4^{\circ}$ & Pernambuco & $97,69 \%$ \\
\hline $5^{\circ}$ & Roraima & $97,39 \%$ \\
\hline $6^{\circ}$ & Minas Gerais & $80,19 \%$ \\
\hline $7^{\circ}$ & Amazonas & $69,58 \%$ \\
\hline $8^{\circ}$ & Espírito Santo & $67,04 \%$ \\
\hline $9^{\circ}$ & Santa Catarina & $61,67 \%$ \\
\hline $10^{\circ}$ & Amapá & $51,24 \%$ \\
\hline $11^{\circ}$ & Bahia & $51,24 \%$ \\
\hline $12^{\circ}$ & Paraná & $51,24 \%$ \\
\hline $13^{\circ}$ & Piauí & $51,24 \%$ \\
\hline $14^{\circ}$ & Rondônia & $51,24 \%$ \\
\hline $15^{\circ}$ & Tocantins & $51,24 \%$ \\
\hline $16^{\circ}$ & Ceará & $44,45 \%$ \\
\hline $17^{\circ}$ & Pará & $36,57 \%$ \\
\hline $18^{\circ}$ & Acre & $3,49 \%$ \\
\hline
\end{tabular}

Fonte: elaboração do autor, a partir dos dados de software.

A partir dos resultados, pode-se concluir que o Mato Grosso foi o estado mais eficiente no uso de crédito rural e capital social para a aquicultura entre os anos de 2010 e 2011. A produção aquícola nesse Estado consiste principalmente na piscicultura em tanques escavados (BARROS et al., 2011), nos quais são produzidos peixes nativos como o Pirarucu (Arapaima gigas), Matrinchã (Brycon orbignianus), Piraputanga (Brycon sp.), Tambaqui (Colossoma macropomum), Piavussu (Leporinus macrocephalus), Pacu (Piaractus mesopotamicus), Curimbatá (Prochilodus linneatus), Pintado (Pseudopatystoma corruscans), e Cachara (Pseudoplatystoma fasciatum), além das espécies exóticas Bagre Americano (Channel catfish), Tilápia (Oreochromis sp.) e o híbrido Tambacu (Tambaqui x 
Pacu) (VALENTI, 2000). Segundo os dois autores citados, no Estado predomina a produção de peixes redondos (Pacu, Tambaqui, e Tambacu) em sistema de cultivo semi-intensivo, no qual os peixes são criados em viveiro escavado com suplementação alimentar através de arraçoamento.

Com esse sistema, o Estado foi o terceiro maior produtor nacional de pescado continental oriundo da aquicultura em 2011, com 48.748 toneladas produzidas (BRASIL, 2012a). Barros et al. (2011), destaca como possíveis causas da evolução da piscicultura no Mato Grosso, principalmente a partir do ano de 2006, a aprovação da Lei Estadual $n^{\circ} 8.464$ de 04/04/2006 que define e disciplina a piscicultura (MATO GROSSO, 2006); e o sancionamento, pelo Governo Estadual, de incentivos fiscais que estimulam a criação, industrialização e o comércio de pescado proveniente da aquicultura, pela isenção da cobrança do Imposto sobre Circulação de Mercadorias e Serviços (ICMS), através da Lei Estadual no 8.684 de 20/07/2007 (MATO GROSSO, 2007).

A Paraíba, apresentando como o $2^{\circ}$ Estado no ranking de eficiência, apresenta uma produção aquícola bastante diversificada, representada tanto por espécies piscícolas exóticas (como tilápias e carpas), quanto por espécies nativas de diversas famílias (peixes redondos, tucunaré, corvina, robalo, peixes ornamentais); e pela carcinicultura, através de sistemas de produção extensivo e semi-intensivo (VALENTI, 2000). No Estado, foi marcante a atuação do governo Estadual, principalmente através da reativação em 2011 do Conselho Estadual de Piscicultura (CONESPA), já criado em 2006, e instalado em 2007, porém inoperante até 2011.

O conselho é formado por 19 membros, os quais representam a Secretaria do Desenvolvimento da Agropecuária e da Pesca (SEDAP), a Secretaria do Turismo e Desenvolvimento Econômico, a Federação dos Pescadores do Estado da Paraíba, o Banco do Brasil, o Banco do Nordeste, a antiga Secretaria Especial de Aquicultura e Pesca (atual Ministério da Pesca e Aquicultura - MPA), a Companhia Nacional de Abastecimento (CONAB), a Universidade Federal da Paraíba (UFPB), a Universidade Federal de Campina Grande (UFCG), a Universidade Estadual da Paraíba (UEPB), o Instituto Brasileiro do Meio Ambiente (IBAMA), e outros organismos, e tem por objetivo desenvolver a piscicultura extensiva em reservatórios públicos, comunitários e de áreas de assentamento, aumentando a oferta de alimentos com proteína de origem animal (PARAÍBA, 2011). Outras instituições também atuaram no desenvolvimento da piscicultura na Paraíba, como a Emater-PB, que ofereceu assistência técnica e planejamento participativo com os aquicultores, buscando recursos através de convênio com o MPA.

No Estado do Maranhão, terceiro colocado no ranking de eficiência, a aquicultura é bastante diversificada, caracterizando-se pela produção de ostras, camarões e pela piscicultura em tanques-rede e em tanques escavados, sendo influenciada pela atuação do Estado através da Agência de Desenvolvimento da Pesca e da Aquicultura (ADEPAQ), a qual é considerada uma decorrência natural da criação da antiga Secretaria Especial de Aquicultura e Pesca em âmbito nacional. Em consonância com a atuação estadual, são impactantes as iniciativas municipais, através de projetos que exploram oportunidades de

Cultura Agronômica, Ilha Solteira, v.24, n.4, p.355-368, 2015 
desenvolvimento local. Entre esses projetos, destacam-se o estímulo à formação de associações e a instalação de projetos casulo (demonstrativos), porém ainda são identificados empecilhos que dificultam a expansão da atividade, como a dificuldade para o licenciamento de novas áreas, oriunda da confusão acerca das atribuições entre órgãos ambientais estaduais e federais, causando com este fato, o embargo de todos os empreendimentos de produção de camarão no polo de Primeira Cruz, no município de Humberto de Campos/MA (MARANHÃO, 2003).

Com base nesses resultados, através dos fatores observados nos três Estados com melhor colocação no ranking, pode-se identificar os principais condicionantes de eficiência como sendo:

$\checkmark$ Produção de espécies nativa e híbrida com nicho de mercado específico e preço de venda diferenciado, além das espécies exóticas já estabelecidas, como as tilápias, carpas, e bagres exóticos;

Utilização de sistemas de produção diversificados, com foco no sistema semiintensivo (tanques escavados com suplementação alimentar através do arraçoamento), o qual permite uma produtividade maior do que a obtida em sistema extensivo (tanques escavados sem suplementação alimentar), porém com uma exigência técnica e sensibilidade menor do que o sistema intensivo (tanques-rede ou sistemas de tanques escavados com alta taxa de renovação de água);

$\checkmark$ Participação ativa do governo estadual e municipal, atuando junto aos órgãos ambientais para facilitar o processo de licenciamento ambiental, junto aos produtores e comunidades interessadas através da capacitação e do fomento organizacional, através de incentivos fiscais ao setor produtivo, bem como de articulação entre as diversas instituições atuantes no setor produtivo pesqueiro buscando a convergência de interesses.

Esses fatores, aliados à exploração das particularidades de clima, recursos naturais e de mercado, contribuem decisivamente para a eficiência do uso do crédito rural e do capital social na aquicultura.

Por outro lado, o estado do Acre apresentou a menor eficiência na utilização do crédito rural e do capital social. A aquicultura no estado teve início em 1979 e ganhou importância a partir de 1995 devido à escassez de peixes nos rios no entorno de rio Branco decorrente da sobrepesca (que alavancou a piscicultura no vale do rio Purus), além do grande número de açudes construídos pelos bovinocultores que ficaram praticamente ociosos, levando os fazendeiros a pressionarem o Governo para que os mesmos fossem povoados com alevinos (BRASIL, 2012b). Assim, a piscicultura acreana é uma atividade recente e em ascensão, vista como um meio de diversificação de renda, em que os produtores iniciam-se sem nenhuma atividade de planejamento. As principais espécies cultivadas são: pirarucu, acará-açu, matrinchã, tambaqui, pacu, tilápia nilótica, pirapitinga, curimatã, piau-açu e pintado. Ainda segundo BRASIL (2012b), os principais desafios da atividade no Acre são:

Normatização Estadual que regulamente a atividade;

Cultura Agronômica, Ilha Solteira, v.24, n.4, p.355-368, 2015 
Resolução dos problemas de cunho fundiário do Estado, haja vista o grande número de posseiros atualmente;

$\checkmark$ Divulgar, de forma mais incisiva, informações referentes ao licenciamento da atividade de Aquicultura no Estado;

$\checkmark$ Ausência de documento de titularidade da propriedade;

$\checkmark$ Vias de acesso que dificultam o escoamento da produção;

$\checkmark$ Dificuldade para obtenção de linhas de crédito para a implantação e operação da atividade.

Comparando os estados mais eficientes (MT, PB e MA) com o de menor eficiência (AC), percebeu-se uma discrepância considerável entre os fatores condicionantes do desempenho, e a correspondência da eficiência técnica do uso do capital social e do crédito rural com a realidade institucional e organizativa.

\section{CONCLUSÃO}

A análise DEA mostra-se um instrumento relevante para a comparação entre as unidades de federação partícipes no crédito rural destinado à aquicultura. Desta forma, na análise de eficiência, os estados de Mato Grosso, Paraíba e Maranhão apresentaram o melhor desempenho, em oposição ao estado do Acre, com menor eficiência.

Nesse contexto, percebe-se que os principais fatores condicionantes de eficiência observados são: o aproveitamento de espécies nativas, com nicho diferenciado e maior valor de mercado; o ordenamento legal da atividade e o apoio através de incentivos fiscais por parte do governo estadual; e a existência de um ambiente institucional bem estruturado e que atenda a demanda regional de informação e assistência técnica e a agilidade nos processos de licenciamento, por meio da participação ativa dos governos municipal e estadual.

Assim, a análise DEA mostrou-se não somente uma ferramenta gerencial, mas também de auxílio governamental, permitindo que além dos valores absolutos de recursos e produção, sejam observados outros condicionantes, que podem passar despercebido perante uma análise comum.

\section{REFERÊNCIAS BIBLIOGRÁFICAS}

BARROS, A. F.; MARTINS, M. I. E. G.; SOUZA, O. M. Caracterização da Piscicultura na microrregião da Baixada Cuiabana, Mato Grosso, Brasil. Boletim Instituto da Pesca, v. 37, n. 3, p.261-273, 2011.

BNDES. Anuário estatístico do crédito rural 2010. Brasil, 2010. 659 p.

SIDONIO, L.; CAVALCANTI, I.; CAPANEMA, L.; MORCH, R.; MAGALHÃES, G.; LIMA, J.; BURNS, V.; ALVES JÚNIOR, A. J.; MUNGIOLI, R. Panorama da aquicultura no Brasil: desafios e oportunidades. BNDES Setorial, v. 35, p.421-463, 2012. Disponível

Cultura Agronômica, Ilha Solteira, v.24, n.4, p.355-368, 2015 
em:

http://www.bndes.gov.br/SiteBNDES/export/sites/default/bndes_pt/Galerias/Arquivos/conh ecimento/bnset/set3512.pdf. Acesso em: 20 nov. 2014.

BRASIL, MINISTÉRIO DA PESCA E AQUICULTURA - MPA. Boletim estatístico da pesca e aquicultura 2011. Brasília: MPA, 2012. 60 p. Disponível em: http://www.mpa.gov.br/files/docs/Boletim_MPA_2011_pub.pdf. Acesso em: 23 nov. 2014. (a)

BRASIL - SISTEMA NACIONAL DE INFORMAÇÃO DA PESCA E AQUICULTURA. AC Licenciamento ambiental da aquicultura. 2012. Disponível em: http://sinpesq.mpa.gov.br/rgp_cms/index.php?option=com_content\&view=article\&id=83\&I temid=93. Acesso em: 25 nov. 2013. (b)

BRASIL. O que é um convênio? 2013. Disponível em: http://www.receita.fazenda.gov.br/pessoajuridica/cnpj/ConvenJuntaBH/Convenios.htm.

Acesso em: 19 nov. 2013.

BRASIL, SISTEMA DE GESTÃO DE CONVÊNIOS E CONTRATOS DE REPASSE SICONV. Convênios e Contratos de Repasse da Administração Pública Federal. Disponível em: http://www.convenios.gov.br. Acesso em: 11 nov. 2014.

CHARNES, A.; COOPER, W.; LEWIN, A. Y.; SEIFORD, L. M. Data envelopment analysis: theory, methodology and applications. London: Kluwer Academic Publishers, $1996.511 \mathrm{p}$.

FARRELL, M. J. The measurement of productive efficiency. Journal of the Royal Statistical Society, London, Series A, Pt. 3, p.253-290, 1957.

MARANHÃO - INSTITUTO INTERAMERICANO DE COOPERAÇÃO PARA A AGRICULTURA - IICA. Desenvolvimento da pesca e da aquicultura no Estado do Maranhão. Documento síntese do Seminário Nacional. 2003. Disponível em: http://www.iica.org.br/docs/publicacoes/publicacoesiica/desenvpescaaquic-ma.pdf. Acesso em: 23 nov. 2014. Brasília: IICA, 2003. 57 p.

MATO GROSSO. Superintendência da Imprensa Oficial do Estado de Mato Grosso. Decreto-Lei Estadual no 8464 de 04 de Abril de 2006. Dispõe, define e disciplina a piscicultura no Estado de Mato Grosso e dá outras providências. Diário Oficial, Cuiabá, n. 23468, p. 1, 2006.

MATO GROSSO. Superintendência da Imprensa Oficial do Estado de Mato Grosso. Decreto-Lei Estadual n 8684 de 20 de Julho de 2007. Dispõe sobre a isenção de ICMS nas

Cultura Agronômica, Ilha Solteira, v.24, n.4, p.355-368, 2015 
operações relativas à comercialização de peixes e jacarés criados em cativeiro, nas condições que especifica. Diário Oficial, Cuiabá, n. 24638, p. 1, 2007.

MEZA, L. A.; BIONDI NETO, L.; MELlO, J. C. C. B. S.; GOMES, E. G. ISYDS Integrated System for Decision Support (SIAD - Sistema Integrado de Apoio a Decisão): a software package for data envelopment analysis model. Pesquisa Operacional, Rio de Janeiro, v. 25, n. 3, p.493-503, 2005.

NEVES JÚNIOR, I. J.; VASCONCELOS, E. S.; BRITO, J. L. Análise da eficiência na geração de retorno aos acionistas das empresas do setor da construção civil com ações negociadas na BMF \& BOVESPA nos anos de 2009 e 2010 por meio da análise envoltória de dados-DEA. In: CONGRESSO BRASILEIRO DE CUSTOS, 19., 2012, Bento Gonçalves/RS. Anais... Bento Gonçalves: ABC, 2012. p.1-8. CD-ROM.

MARQUES, R. Economia Experimental e Reciprocidade: Uma meta-análise. Socius Working papes, n. 2, 2001. Disponível em: http://hdl.handle.net/10400.5/2049. Acesso em: 30 ago. 2015.

MILANI, C. R. S. Nem cola, nem lubrificante sociológico, mas campo eletromagnético: as metáforas do Capital Social no campo do desenvolvimento local. Santa Cruz do Sul: REDES, Santa Cruz do Sul, v. 12, n. 1, p.195-224, 2007.

PARAÍBA. Governo lança Programa de Piscicultura e Aquicultura e instala Conselho Estadual. 2011. Disponível em: http://www.paraiba.pb.gov.br/10567/governo-lancaprograma-de-piscicultura-e-aquicultura-e-instala-conselho-estadual.html. Acesso em: 27 nov. 2014.

REZENDE, G. C. Crédito rural subsidiado e preço da terra no Brasil. IPEA/INPES, 1981. Disponível em: http://repositorio.ipea.gov.br/bitstream/11058/1031/1/td_0041.pdf. Acesso em: 30 ago. 2015.

VAlENTI, V. C.; POLI, C. R.; PEREIRA, J. A.; BORGHETTI, J. R. Aquicultura no Brasil: bases para um desenvolvimento sustentável. Brasília: Conselho Nacional de Desenvolvimento Científico e Tecnológico, 2000. 399 p.

Cultura Agronômica, Ilha Solteira, v.24, n.4, p.355-368, 2015 
